\title{
Biochar induced improvement in root system architecture enhances nutrient assimilation by cotton plant seedlings
}

Lei Feng ${ }^{1,2}$, Wanli Xu², Guangmu Tang ${ }^{2^{*}}$, Meiying $\mathrm{Gu}^{3}$ and Zengchao Geng ${ }^{1 *+}$

\begin{abstract}
Background: Raising nitrogen use efficiency of crops by improving root system architecture is highly essential not only to reduce costs of agricultural production but also to mitigate climate change. The physiological mechanisms of how biochar affects nitrogen assimilation by crop seedlings have not been well elucidated.

Results: Here, we report changes in root system architecture, activities of the key enzymes involved in nitrogen assimilation, and cytokinin (CTK) at the seedling stage of cotton with reduced urea usage and biochar application at different soil layers $(0-10 \mathrm{~cm}$ and $10-20 \mathrm{~cm})$. Active root absorption area, fresh weight, and nitrogen agronomic efficiency increased significantly when urea usage was reduced by $25 \%$ and biochar was applied in the surface soil layer. Glutamine oxoglutarate amino transferase (GOGAT) activity was closely related to the application depth of urea/ biochar, and it increased when urea/biochar was applied in the $0-10 \mathrm{~cm}$ layer. Glutamic-pyruvic transaminase activity (GPT) increased significantly as well. Nitrate reductase (NR) activity was stimulated by CTK in the very fine roots but inhibited in the fine roots. In addition, AMT1;1, gdh3, and gdh2 were significantly up-regulated in the very fine roots when urea usage was reduced by $25 \%$ and biochar was applied.
\end{abstract}

Conclusion: Nitrogen assimilation efficiency was significantly affected when urea usage was reduced by $25 \%$ and biochar was applied in the surface soil layer at the seedling stage of cotton. The co-expression of gdh 3 and gdh2 in the fine roots increased nitrogen agronomic efficiency. The synergistic expression of the ammonium transporter gene and $g$ dh 3 suggests that biochar may be beneficial to amino acid metabolism.

Keywords: Gdh2,3, Nitrogen assimilation enzyme, Cytokinin, Fine root, Biochar

\section{Background}

Biochar is produced via dry carbonization, pyrolysis, or gasification of biomass, whereas hydrochar is produced as slurry in water by hydrothermal carbonization of biomass under press. Biochar is fine-grained, porous, of high

\footnotetext{
*Correspondence: tangjunhui5120@126.com; mayi@nwafu.edu.cn

${ }^{\dagger}$ Guangmu Tang and Zengchao Geng contributed equally to this work.

${ }^{1}$ College of Natural Resources and Environment, Northwest Key

Laboratory of Plant Nutrition and Agro-Environment, Ministry

of Agriculture, Northwest A \& F University, Yangling 712100, China

${ }^{2}$ Xinjiang Academy of Agricultural Sciences Institute of Soil Fertilizer

and Water Conservation, Urumqi 830092, China

Full list of author information is available at the end of the article
}

specific surface area, and rich in functional groups and nutrients such as nitrogen, phosphorus, and potassium [1-3]. Biochar application has been found to be an effective, environmentally-friendly agricultural management technology for improving nitrogen utilization efficiency while reducing nitrogen fertilizer application. It not only improves nitrogen absorption but also enhances nitrogen assimilation by regulating root morphology and related physiological and metabolic processes [4-6]. Biochar has been proposed as a soil amendment to enhance nutrient retention, reduce nutrient losses, improve soil fertility and crop growth, and sequestrate carbon [7, 8]. In some cropping systems, biochar addition helps to reduce

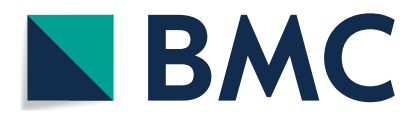

(c) The Author(s) 2021. Open Access This article is licensed under a Creative Commons Attribution 4.0 International License, which permits use, sharing, adaptation, distribution and reproduction in any medium or format, as long as you give appropriate credit to the original author(s) and the source, provide a link to the Creative Commons licence, and indicate if changes were made. The images or other third party material in this article are included in the article's Creative Commons licence, unless indicated otherwise in a credit line to the material. If material is not included in the article's Creative Commons licence and your intended use is not permitted by statutory regulation or exceeds the permitted use, you will need to obtain permission directly from the copyright holder. To view a copy of this licence, visit http://creativecommons.org/licenses/by/4.0/. The Creative Commons Public Domain Dedication waiver (http://creativeco mmons.org/publicdomain/zero/1.0/) applies to the data made available in this article, unless otherwise stated in a credit line to the data. 
nitrogen fertiliser input while maintaining productivity [9] as biochar serves as a good complement to site preparation techniques that are frequently used for capturing nitrogen from nitrate so as to increase rhizosphere nitrogen bioavailability in alkaline soils [10]. According to other reports, biochar application level influences soil nutrient and plant root phenotype [11, 12]. Moreover, studies suggest that biochar changes crop nitrogen utilization efficiency and increases rhizosphere microbial community diversity $[13,14]$ which is strongly associated with root order [15]. Biochar increases microbial biomass [16] and especially the abundance of ammonia-oxidizing bacteria $(\mathrm{AOB})$ which are closely related to the nitrogen cycle [17] and cause great variation in the $\mathrm{NO}_{3}{ }^{-}-\mathrm{N} /$ $\mathrm{NH}_{4}{ }^{+}-\mathrm{N}$ ratio in the rhizosphere of different root orders. Though there are many studies on the effects of AOB on the $\mathrm{NO}_{3}{ }^{-}-\mathrm{N} / \mathrm{NH}_{4}{ }^{+}-\mathrm{N}$ ratio, little is known about the mutual effects between mineral nitrogen, rhizosphere $\mathrm{AOB}$ community, and root order when biochar is applied in gray desert soils.

The biochar-induced changes in the interaction between mineral nitrogen and hormones may influence root development along with nitrogen assimilation [18, 19]. For instance, biochar addition alters root morphology (larger specific root length, smaller root diameter, and lower root tissue mass density) to facilitate nitrogen uptake, indicating good proliferation of the roots regardless of the fertilization level [20, 21]. Di Lonardo et al. [22] found that biochar decreased the ethylene concentration and increased the number of roots of tissue-cultured poplar, indicating that root phenotype is significantly affected by biochar. It is suggested that biochar changes during root development, which may contribute to the nitrogen cycle and particularly help to increase the opportunity of capturing nitrogen from fertilizer and soil $[23,24]$. However, there is still insufficient evidence supporting that biochar influences nitrogen metabolism via inducing root phenotypic changes.

Additionally, more key links may exist between biochar and the interaction of nitrogen metabolism and gene expression of root phenotype [25-27], and the effect of biochar on the physiological activities (nitrogen availability and auxin changes) of fine roots is found to be more significant $[28,29]$. Recent research reported that 50 and $100 \mathrm{~g} \mathrm{~kg}^{-1}$ of biochar had the same effect in improving nitrogen metabolism, indicating that such effect of biochar may be dose-independent but hormone activation-associated [30]. An investigation demonstrated that biochar addition improved nitrogen assimilation by boosting the activities of glutamate dehydrogenase $(\mathrm{GDH})$, glutamine synthetase (GS), glutamine oxoglutarate aminotransferase (GOGAT), and nitrate reductase (NR) [31]. Hashem et al. [32] revealed that biochar enhanced the nitrogen assimilation efficiency of chickpeas by increasing the NR activity. An in-depth examination indicates that the DOMs of biochar promote nitrogen assimilation and improve nitrogen efficiency by stimulating NR and GS gene expression [33]. Though there are large numbers of reports on enzymes in various plant organs and crop species, the mechanism of nitrogen metabolism regulation by biochar-induced changes in root phenotype remains to be unraveled.

Biochar influences the level and spatial distribution pattern of hormones, which may be the major factor interfering with the activities of the key enzymes involved in nitrogen metabolism [34, 35]. Waqas et al. [36] believed that changes in jasmonic acid signal in their study reflected an alleviating effect of biochar on biotic stress. Recently, studies show that biochar stimulates the gibberellins pathway and promotes the growth of tomato and wheat plants [37, 38]. Conversely, Hale et al. [39] found that $600{ }^{\circ} \mathrm{C}$-pyrolysed pine sawdust biochar had no effect on auxin synthesis. Earlier research emphasizes that the balance between root function and root growth depends on the ethylene signaling pathway and enhanced $\mathrm{H}_{2} \mathrm{O}_{2}$ accumulation [40]. Although biochar-independent changes in plant endogenous hormones occur, it is unclear whether biochar can interfere with CTK metabolism and further affect the GDH and ammonium transporter (AMT) coding genes.

Some studies showed that GDH was not detected in each organ compared with the wild type with the gdh1-2-3 mutant. Root GDH activity reduction of $25 \%$ was only achieved in the gdh2 mutant, while activity increase of $30 \%$ in the root system was achieved in the gdh3 mutant [41]. Sun et al. [25] found that the nitrogen metabolism-related omics characteristics and transcription levels (zmGS1and zmAS1) in maize were significantly up-regulated when nitrogen fertilizer was reduced and biochar was applied. Transcriptomic analysis of tomato by Jaiswal et al. [27] demonstrated that biochar has a priming effect on gene expression; the group also found that the up-regulated genes are associated with plant growth such as jasmonic acid, CTK, auxin, and cell wall. Kumar et al. demonstrated that AMT1 affects not only the interaction between $\mathrm{NH}_{4}{ }^{+}-\mathrm{N}_{\text {and }} \mathrm{NO}_{3}{ }^{-}-\mathrm{N}$ during lateral root growth but also that between auxin and $\mathrm{NH}_{4}{ }^{+}$in rice roots [42]. Some studies showed that biochar regulates plant genes by interfering with microbial signals under abiotic stress [43, 44]. Thus, biochar may affect the synergistic effect of AMT and GDH genes by multiple ways. However, the mechanism of biocharmediated root nitrogen metabolism has not yet been elucidated. Although it has been widely reported that there are significant differences in nutrient uptake, nitrogen storage, and phenotype between root orders [45, 46], 
there are few studies on nitrogen metabolism or nitrogen assimilation of different root orders under reduction of nitrogen application, which makes it impossible for us to fully understand the mechanism of nitrogen metabolism under the condition of nitrogen reduction with biochar addition.

The objectives of this study were to evaluate the changes in soil parameters $\left(\mathrm{NH}_{4}{ }^{+}, \mathrm{NO}_{3}{ }^{-}\right.$, and $\mathrm{AOB}$ abundance), nitrogen-metabolizing enzymes in cotton roots (NR, GDH, glutamic-pyruvic transaminase (GPT), and GS), and cotton root biological characters (root active absorbing area, biomass, and nitrogen agronomic efficiency) caused by biochar addition with the reduction of urea. Furthermore, the effects of cotton AMT and $g d h$ on the biochar-induced nitrogen metabolism were investigated so as to learn the consistence and difference between the expressions of $A M T$ and $g d h$ under the ammonium assimilation pathway and how CTK-stimulated nitrate metabolism contributes to seedling growth. Three hypotheses were tested: (i) biochar addition would alter soil biochemical properties, have a positive effect on the soil nitrogen status, and increase the AOB abundance; (ii) the biochar-induced effects would favor the root intraspecific variation-caused crosstalk between $A M T 1 ; 1$ and $g d h 2$; and (iii) seedlings in the treatments with biochar application and reduced urea usage would show a higher nitrogen metabolism and growth rate.

\section{Materials and methods Plant material}

Seeds of Gossypium hirsutum 49, purchased from Xinjiang Jiu He Seeds Co. Ltd., Xinjiang Uygur Autonomous Region, China, were surface sterilized for $20 \mathrm{~min}$ in sterile water and placed on Petri dishes. After 48 to $72 \mathrm{~h}$ of dormancy release at $4{ }^{\circ} \mathrm{C}$ in the dark, the plates were transferred to a growth pot in a greenhouse for germination.

\section{Experimental design}

The plastic pots $(21 \mathrm{~cm}$ in height and $20 \mathrm{~cm}$ in diameter) used in this trial each contained $7.5 \mathrm{~kg}$ gray desert soil. The following treatments were set up:

ck: neither urea nor biochar was applied; sb: $3.76 \mathrm{~g}$ urea $\mathrm{kg}^{-1}$ soil applied in the $0-10 \mathrm{~cm}$ soil layer;

bb: $3.76 \mathrm{~g}$ urea $\mathrm{kg}^{-1}$ soil applied in the $10-20 \mathrm{~cm}$ soil layer;

soa: $25 \%$ less urea as compared with sb plus $37.28 \mathrm{~g}$ biochar $\mathrm{kg}^{-1}$ soil applied in the $0-10 \mathrm{~cm}$ soil layer; sob: $50 \%$ less urea as compared with sb plus $37.28 \mathrm{~g}$ biochar $\mathrm{kg}^{-1}$ soil applied in the $0-10 \mathrm{~cm}$ soil layer; boa: $25 \%$ less urea as compared with bb plus $37.28 \mathrm{~g}$ biochar $\mathrm{kg}^{-1}$ soil applied in the10-20 cm soil layer; bob: $50 \%$ less urea as compared with bb plus $37.28 \mathrm{~g}$ biochar $\mathrm{kg}^{-1}$ soil applied in the10-20 cm soil layer;

The properties of the soil and biochar obtained by pyrolysis of cotton straw at $450{ }^{\circ} \mathrm{C}$ used are shown in Table 1 . Twelve healthy cotton seedlings were transferred to each pot and then thinned to five after establishment.

The pots were randomly placed in a nursery in Xinjiang Agricultural University (E $43^{\circ} 49^{\prime} 07^{\prime \prime}$, N 81 $51^{\prime} 16^{\prime \prime}$ ). In the meanwhile, soil moisture content is maintained at $60 \% \sim 65 \%$ of field water capacity, $14 \mathrm{~h}$ of light and $10 \mathrm{~h}$ of darkness, the temperature is maintained at $15{ }^{\circ} \mathrm{C}$ to $30^{\circ} \mathrm{C}$. After 20 days of growth, the cotton plants were removed from the pots and separated into above- and belowground fractions. After rhizosphere soils were collected, the roots were carefully washed under running water and further divided into fines roots $(d=0.1-2 \mathrm{~mm})$ and very fine roots $(d<0.1 \mathrm{~mm})$. Segments $(20 \mathrm{~mm}$ in length from the apex) of both the fine and very fine roots were stored in liquid nitrogen before high-throughput sequencing.

\section{Enzyme activity analysis}

For crude enzyme extraction, root samples were pretreated with $2 \mathrm{~mL}$ imidazole in a cold mortar over ice and ground after adding $0.05 \mathrm{~mol} / \mathrm{L} \mathrm{HCl}(\mathrm{pH} 7.2)$. The homogenate was left to stand for $30 \mathrm{~min}$, filtered through two layers of gauze, and centrifuged at $12,000 \mathrm{~g}$ for $20 \mathrm{~min}$. All the above operations were carried out at $4{ }^{\circ} \mathrm{C}$.

The reaction mixture for GOGAT activity determination consisted of $0.4 \mathrm{~mL} 20 \mathrm{mmol} / \mathrm{L} \mathrm{L}$-glutamine, $0.5 \mathrm{~mL}$ $20 \mathrm{mmol} / \mathrm{L} \alpha$-ketoglutaric acid, $0.1 \mathrm{~mL} 10 \mathrm{mmol} / \mathrm{L} \mathrm{KCl}$, $0.2 \mathrm{~mL} 3 \mathrm{mmol} / \mathrm{L} \mathrm{NADH}, 0.3 \mathrm{~mL}$ crude enzyme solution, and $1.5 \mathrm{~mL} 25 \mathrm{mmol} / \mathrm{L}$ tris- $\mathrm{HCl}$ buffer $(\mathrm{pH}=7.6)$. After the reaction was initiated, enzyme activity was measured continuously for a time period during which one

Table 1 Chemical properties of the soil and the biochar used in this study

\begin{tabular}{|c|c|c|c|c|c|c|c|}
\hline Material & $\begin{array}{l}\text { Organic } \\
\text { matter/g kg }\end{array}$ & $\begin{array}{l}\text { Available } \\
\text { nitrogen/mg } \\
\text { kg }^{-1}\end{array}$ & $\begin{array}{l}\text { Available } \\
\text { phosphorus/mg } \\
\mathrm{kg}^{-1}\end{array}$ & $\begin{array}{l}\text { Available } \\
\text { potassium/ mg } \\
\mathbf{k g}^{-1}\end{array}$ & Total salt/g kg ${ }^{-1}$ & $\mathrm{pH}$ & $\begin{array}{l}\text { Soil electrical } \\
\text { conductivity/mS } \\
\mathrm{cm}^{-1}\end{array}$ \\
\hline Soil & 8.54 & 54.33 & 43.12 & 102.45 & 11.02 & 8.6 & 0.33 \\
\hline Biochar (Bc) & 406.33 & 36.57 & 918.74 & 12.30 & 60.97 & 10.5 & 3.70 \\
\hline
\end{tabular}


extinction value at $340 \mathrm{~nm}$ was recorded every $20 \mathrm{~s}$ with a photometer until the optical density showed a steady sevenfold decrease. GOGAT activity was presented as the produced amount of the reduction product of NADH per unit of reaction time.

Assay of NR activity was carried out according to Cervilla et al. [47]. The reaction mixture in a final volume of $0.8 \mathrm{~mL}$ consisted of $0.5 \mathrm{~mL} 100 \mathrm{mmol} / \mathrm{L}$ potassium-phosphate buffer (pH 7.5), $0.1 \mathrm{~mL} 100 \mathrm{mmol} / \mathrm{L} \mathrm{KNO}_{3}, 0.1 \mathrm{~mL}$ $2 \mathrm{mmol} / \mathrm{L} \mathrm{NADH}$, and $0.1 \mathrm{~mL}$ of the crude enzyme solution. After incubation at $25^{\circ} \mathrm{C}$ for $20 \mathrm{~min}$, the reaction was terminated with $0.05 \mathrm{~mL} 1 \mathrm{~mol} / \mathrm{L}$ zinc acetate. The reaction solution was centrifuged at $3000 \mathrm{~g}$ for $10 \mathrm{~min}$, and $0.6 \mathrm{~mL}$ supernatant was diluted to $1 \mathrm{~mL}$ with distilled water. The nitrite formed was diazotized with sulfanilamide and reacted with $\mathrm{N}$-(1- naphthyl) ethylene diamine dihydrochloride to produce azo dye which was measured spectrophotometrically at $540 \mathrm{~nm}$. Glutamate dehydrogenase activity was also determined according to Cervilla et al.. Glutamic-pyruvic transaminase activity was measured according to Kasim and Dowidar and presented as the amount of pyruvate produced per unit time after 300-min reaction [48].

The results of the enzyme activities are presented as means \pm standard errors $(n=5)$.

\section{Determination of cytokinin content}

Cytokinin content was determined by enzyme linked immunosorbent assaysaccording to Yang [49]. Briefly, root samples were rinsed with cold tap water to remove adhesive soil particles, homogenized with a mortar and a pestle in liquid nitrogen, extracted with phosphate buffer $(\mathrm{pH}=5)$ at $-20{ }^{\circ} \mathrm{C}$ for $1 \mathrm{~h}$, centrifuged at $10,000 \times g$ and $4{ }^{\circ} \mathrm{C}$ for $15 \mathrm{~min}$, incubated with horseradish peroxidase again at $-20{ }^{\circ} \mathrm{C}$ for $30 \mathrm{~min}$. Finally, cytokinin was quantified by enzyme label reader (Neogen 4700, USA).

\section{High-throughput sequencing RNA extraction}

Total RNA was extracted from the cotton root using TRIzol ${ }^{\circledR}$ Reagent (Ambion, USA) according to the manufacturer's instructions and genomic DNA was removed using DNase I. Then, RNA quality and quantity were determined with a 2100 Bioanalyser (Agilent, USA) and a NanoDrop ND-2000 spectrophotometer (Thermo Fisher Scientific, USA), respectively. Only high-quality RNA sample $($ OD260/280 $=1.8 \sim 2.2$, OD $260 / 230 \geq 2.0$, $\mathrm{RIN} \geq 6.5,28 \mathrm{~S}: 18 \mathrm{~S} \geq 1.0$, and $>1 \mu \mathrm{g}$ ) was used for preparation of the sequencing library.

\section{Library preparation and Illumina sequencing}

RNA-seq transcriptome library was prepared with the TruSeq $^{\mathrm{TM}}$ RNA Sample Preparation Kit from Illumina
(San Diego, CA) using $1 \mu \mathrm{g}$ of total RNA. Briefly, messenger RNA was enriched with magnetic oligo (dT) beads and fragmented into short segments with fragmentation buffer. Double-stranded cDNA was synthesized using the SuperScript double-stranded cDNA synthesis kit (Invitrogen, CA) with random primers. The synthesized cDNA was then purified, end repaired, phosphorylated, and polyA tailed. Libraries were size selected on $2 \%$ Low Range Ultra Agarose and PCR amplified using Phusion DNA polymerase (NEB). After quantification with TBS380, the paired-end RNA-seq library was sequenced with the Illumina HiSeq xten/NovaSeq 6000 sequencer $(2 \times 150$ bp read length).

\section{Read mapping}

The raw reads were processed and quality controlled by SeqPrep (https://github.com/jstjohn/SeqPrep) and Sickle (https:/github.com/najoshi/sickle) with default parameters to obtain high-quality clean reads. Then, clean reads were aligned to the reference genome using HISAT2[50]. The aligned reads were assembled using the referencebased assembler StringTie [51].

\section{Differential expression analysis}

To identify differentially expressed genes (DEGs) between two different samples, the expression level of each transcript was calculated based on transcripts per million reads (TPM). Gene abundances were quantified using RSEM software [52]. Essentially, differential expression analysis was performed using DESeq2/DEGseq/EdgeR with $\mathrm{Q} \leq 0.05$, and genes with $\left|\log _{2} \mathrm{FC}\right|>1$ and $\mathrm{Q} \leq 0.05$ (DESeq2 or EdgeR)/Q $\leq 0.001$ (DEGseq) were considered DEGs [53].

\section{Determination of soil $\mathrm{NO}_{3}{ }^{-}-\mathrm{N}$ and $\mathrm{NH}_{4}{ }^{+}-\mathrm{N}$}

The collected rhizosphere soil samples where plant were grown for 20 days were extracted with $1 \mathrm{mmol} / \mathrm{L} \mathrm{KCl}$ solution, and concentrations of $\mathrm{NO}_{3}{ }^{-}$and $\mathrm{NH}_{4}{ }^{+}$were colorimetrically measured with a CleverChem 380 random access analyser (Dechem-Tech, Hamburg, Germany) according to the manufacturer's instructions [54].

\section{Ammonia-oxidizing bacteria}

The rhizosphere soil samples were used for analysis of AOB. The qPCR reaction mixture consisted of $10 \mu \mathrm{L}$ Quantitect SYBR green master mix (Qiagen, Valencia, CA, USA), $0.25 \mu \mathrm{L}$ forward and reverse primers, $2 \mu \mathrm{L}$ DNA template ( 10-40 ng DNA), and nucleasefree $\mathrm{H}_{2} \mathrm{O}$ to a final volume of $20 \mu \mathrm{L}$. Standard curves $\left(R^{2}>0.99\right)$ were generated by amplifying using the serial dilutions of the synthesized copies of the target gene sequences. All qPCR reactions were performed in quintuplicate and amplification efficiencies ranged from 80 
to $90.8 \%$. Amplification specificity was determined using melt curve analysis. The $16 \mathrm{~s}$ rDNA fragments of AOB were amplified by nested PCR (nest-PCR) and the primer sequence was used. F27/R1492 is a common primer used for bacteria. CTO189F/CTO654R is a specific primer for AOB; F341/R518 is a V3 region specific primer for $16 \mathrm{~s}$ rDNA.

AOB primers CTO189F-5 'GCAGRAAAGYAGGGG ATCG and CTO654R-5 'CTAGGYTTGTAGTTTCAA ACGC were used [55].

\section{Statistical analysis}

Genes with a Bonferroni $P$ value $<0.05$ were considered differentially expressed [56]. In addition to the paired t-test approach, the rank product method was used to detect differentially expressed genes according to the different levels of FDR. Transcripts satisfying both the above family-wise error rate level and FDR $<0.0001 \%$ were presented to achieve an optimal interpretation of the transcriptome. Genes were sorted by descending rank product values to provide a hierarchical list based on both strength and reproducibility, which was used as an input to identify groups of genes with the same or related annotated functions. BlastX was used to combine Unigene Sequence with NR (Non-redundant Protein Sequence Database in GenBank), Swiss-Prot (Swiss-Prot Protein Sequence Database), KEGG (Kyoto Encyclopedia of Genes and Genomes) and COG (Cluster ofOrthologous Groups of proteins were compared in the database (Evalue $<1 \mathrm{E}-5)$ to obtain the proteins with the highest sequence similarity to Unigene, thereby obtaining the protein functional annotation information of the Unigene. According to the NR annotation information,
Blast2Go software was used for GO annotation. After the GO information of each Unigene was obtained, WEGO software was used for GO function classification statistic [57].

\section{Results \\ Changes of $\mathrm{NO}_{3}{ }^{-}-\mathrm{N}$ and $\mathrm{NH}_{4}{ }^{+}-\mathrm{N}$ in the rhizosphere}

There were clear differences in $\mathrm{NO}_{3}{ }^{-}-\mathrm{N}$ content between the rhizosphere of fine roots and that of very fine roots in the biochar application treatments (Table 2). In addition, there was strong interaction between biochar application amount and application depth. Rhizosphere $\mathrm{NO}_{3}{ }^{-} \mathrm{N}$ content increased when biochar was applied regardless of the application depth. In the 0-10 cm layer, $\mathrm{NO}_{3}{ }^{-}-\mathrm{N}$ content was slightly higher in the rhizosphere of the very fine roots than in that of the fine roots. Rhizosphere $\mathrm{NO}_{3}{ }^{-}-\mathrm{N}$ content increased significantly when urea was reduced by $25 \%$ in the $0-10 \mathrm{~cm}$ layer. The content of $\mathrm{NO}_{3}{ }^{-} \mathrm{N}$ in boam was $42 \%$ higher than that in bbm. In the $10-20 \mathrm{~cm}$ layer, the highest $\mathrm{NO}_{3}{ }^{-}-\mathrm{N}$ content in the rhizosphere of the very fine roots in bob was $6.33 \mathrm{mg} \mathrm{L}^{-1}$. This indicates that results of crop nutrient uptake and utilization based on fine roots $(d<2 \mathrm{~mm})$ may not be sufficient. Results based on further divided root functional segments $(d<0.1 \mathrm{~mm}$ and $0.1<d<2 \mathrm{~mm})$ may provide a clearer picture on the changes of nitrogen concentration in the rhizosphere.

Ammonium nitrogen showed a similar trend to that of $\mathrm{NO}_{3}{ }^{-} \mathrm{N}$ in the rhizosphere. The content of $\mathrm{NH}_{4}{ }^{+}-\mathrm{N}$ in the rhizosphere of both the fine and very fine roots was significantly higher in the treatments with $25 \%$ urea reduction than in ck. In the $0-10 \mathrm{~cm}$ soil layer, $\mathrm{NH}_{4}{ }^{+}-\mathrm{N}$ decreased by $0.003 \mathrm{mg} \mathrm{L}^{-1}$ in the rhizosphere of the very

Table 2 Soil mineral nitrogen $\left(\mathrm{NO}_{3}{ }^{-}\right.$and $\left.\mathrm{NH}_{4}{ }^{+}\right)$in the rhizosphere of very fine $(d<0.1 \mathrm{~mm})$ and fine $(0.1<d<2 \mathrm{~mm})$ roots of Gossypium hirsutum in the different treatments when urea/biochar was applied in the $0-10$ or $1-20 \mathrm{~cm}$ soil layer

\begin{tabular}{|c|c|c|c|c|c|c|c|c|}
\hline \multirow[t]{2}{*}{ Soil layers } & \multicolumn{4}{|c|}{$\mathrm{NO}_{3}{ }^{-}$concentration $(\mathrm{mg} / \mathrm{L})$} & \multicolumn{4}{|c|}{$\mathrm{NH}_{4}^{+}$concentration (mg/L) } \\
\hline & 0 & $10 \mathrm{~cm}$ & 10 & $20 \mathrm{~cm}$ & 0 & $10 \mathrm{~cm}$ & 10 & $20 \mathrm{~cm}$ \\
\hline Treatment & $<0.1 \mathrm{~mm}$ & $0.12 \mathrm{~mm}$ & $<0.1 \mathrm{~mm}$ & $0.12 \mathrm{~mm}$ & $<0.1 \mathrm{~mm}$ & $0.12 \mathrm{~mm}$ & $<0.1 \mathrm{~mm}$ & $0.12 \mathrm{~mm}$ \\
\hline$c k$ & $0.13(0.04) d$ & $0.21(0.11) d$ & $0.11(0.01) d$ & $0.42(0.03) d$ & $0.076(0.021) b c$ & $0.083(0.009) b$ & $0.084(0.013) b$ & $0.088(0.014) b$ \\
\hline s & $7.33(1.02) \mathrm{a}$ & $8.22(0.58)$ a & $3.46(0.33) b c$ & $4.62(0.29) \mathrm{C}$ & $0.061(0.005) c$ & $0.069(0.003) c$ & $0.041(0.009) \mathrm{c}$ & $0.042(0.017) c$ \\
\hline b & $3.28(0.31) c$ & $3.75(1.04) \mathrm{C}$ & $1.04(0.19) \mathrm{cd}$ & $1.09(0.38) d$ & 0.089 (0.009) b & $0.095(0.013) a b$ & $0.092(0.016) a b$ & 0.099 (0.006) ab \\
\hline soa & $7.65(0.82)$ a & $9.58(0.54)$ a & $4.12(0.08) b$ & $9.77(0.36)$ a & $0.104(0.033) \mathrm{a}$ & $0.127(0.012) \mathrm{a}$ & $0.107(0.029)$ a & $0.101(0.024) a b$ \\
\hline sob & $5.62(1.12) b$ & $6.33(0.24) b$ & $3.09(0.25) b c$ & $4.73(0.17) \mathrm{c}$ & $0.092(0.005) a b$ & $0.086(0.015) b$ & $0.085(0.008) b$ & 0.089 (0.019) b \\
\hline boa & $5.09(0.49) b c$ & $5.89(0.78) b$ & $3.01(0.37) b c$ & 7.09 (0.28) b & $0.048(0.008) d$ & $0.054(0.002) c$ & $0.117(0.028) \mathrm{a}$ & 0.125 (0.003)a \\
\hline bob & $4.16(0.08) b c$ & $4.57(0.04) b c$ & $6.33(0.19) \mathrm{a}$ & $9.69(0.05)$ a & $0.083(0.021) b$ & $0.076(0.004) b c$ & $0.104(0.002) \mathrm{a}$ & $0.118(0.002) a$ \\
\hline
\end{tabular}

Note: The different lowercase letters indicate significant differences between treatments with a confidence interval at $P<0.05$

There are seven treatments: $\mathrm{ck}$ (control), sb (conventional $3.76 \mathrm{~g}$ urea kg $\mathrm{kg}^{-1}$ soil applied in the $0-10 \mathrm{~cm}$ soil layer), bb (conventional nitrogen fertilization in the $10-20 \mathrm{~cm}$ soil layer), soa (urea was reduced by $25 \%$ on the basis of sb plus $37.28 \mathrm{~g}$ biochar kg $\mathrm{kg}^{-1}$ soil), sob (urea was reduced by $50 \%$ on the basis of sb plus $37.28 \mathrm{~g}$ biochar kg $\mathrm{kg}^{-1}$ soil), boa (urea was reduced by $25 \%$ on the basis of bb plus $37.28 \mathrm{~g}$ biochar $\mathrm{kg}^{-1}$ soil), and bob (urea was reduced by $50 \%$ on the basis of bb with $37.28 \mathrm{~g}$ biochar $\mathrm{kg}^{-1}$ soil). Results are presented as mean values for five plants with SE 
fine roots while increased by $0.026 \mathrm{mg} \mathrm{L}^{-1}$ in the rhizosphere of the fine roots in the biochar treatments as compared with the $100 \%$ urea treatment. When biochar was applied in the $10-20 \mathrm{~cm}$ layer, $\mathrm{NH}_{4}{ }^{+}-\mathrm{N}$ decreased by $59 \%$ and $57 \%$ in boaf and boam, respectively (Table 2).

\section{Copy number of AOB}

The copy number of $\mathrm{AOB}$ in the rhizosphere of the very fine and fine roots was $4.71-8.65 \times 10^{7}$ and $4.53-$ $10.8 \times 10^{7}$, respectively (Table 3 ), which indicates that fine roots may have provided more ecological niches for AOB. The AOB copy number in the rhizosphere of very fine roots in boa was $5.44 \times 10^{7}$, which was not much different from those in soa, sob, and bob and was slightly higher than that in ck. Compared with that in ck, the amount of $\mathrm{AOB}$ in the rhizosphere of fine roots in both layers decreased in the conventional urea application treatment, while that in the $25 \%$ and $50 \%$ urea reduction treatments (applied to the $0-10 \mathrm{~cm}$ layer) increased 1.86and 1.78-fold, respectively. The amount of AOB in the rhizosphere of fine roots in boa was up to $1.08 \times 10^{8}$.

\section{The effects of urea reduction combined with biochar application on the key enzymes involved in nitrogen metabolism}

Urea reduction combined with biochar application strongly interfered with the nitrogen metabolism in seedling roots, causing significant differences in the activities of the key enzymes involved in nitrogen metabolism. Compared with that in the conventional urea application treatment, the GDH activity in the very fine roots increased twofold in the $25 \%$ urea reduction treatment, while that in the fine roots decreased generally, with the largest decrease percentage of $91 \%$ in sobm. The GDH

Table 3 Copy numbers of ammonia-oxidizing bacteria (AOB) in the rhizosphere of very fine $(d<0.1 \mathrm{~mm})$ and fine $(0.1<d<2 \mathrm{~mm})$ roots of Gossypium hirsutum in the different treatments

\begin{tabular}{lll}
\hline Treatment & Very fine root & Fine root \\
\hline ck & $4.71 \times 10^{7}$ & $5.21 \times 10^{7}$ \\
s & $8.65 \times 10^{7}$ & $4.98 \times 10^{7}$ \\
b & $6.86 \times 10^{7}$ & $4.53 \times 10^{7}$ \\
soa & $7.29 \times 10^{7}$ & $9.70 \times 10^{7}$ \\
sob & $6.58 \times 10^{7}$ & $9.28 \times 10^{7}$ \\
boa & $5.44 \times 10^{7}$ & $1.08 \times 10^{8}$ \\
bob & $7.83 \times 10^{7}$ & $6.95 \times 10^{7}$ \\
\hline
\end{tabular}

The treatments are as follows: $\mathrm{ck}$ (control), sb (conventional $3.76 \mathrm{~g}_{\text {urea }} \mathrm{kg}^{-1}$ soil applied in the $0-10 \mathrm{~cm}$ soil layer), bb (conventional nitrogen fertilization in the $10-20 \mathrm{~cm}$ soil layer), soa (urea was reduced by $25 \%$ on the basis of sb plus $37.28 \mathrm{~g}_{\text {biochar kg }}^{-1}$ soil), sob (urea was reduced by $50 \%$ on the basis of sb plus $37.28 \mathrm{~g}$ biochar kg $\mathrm{k}^{-1}$ soil), boa (urea was reduced by $25 \%$ on the basis of bb plus $37.28 \mathrm{~g}_{\text {biochar kg }}^{-1}$ soil), and bob (urea was reduced by $50 \%$ on the basis of bb with $37.28 \mathrm{~g}_{\text {biochar kg }}^{-1}$ soil) activity decreased significantly $(P<0.05)$ when urea application was reduced by $50 \%$ (Fig. $1 \mathrm{~A}$ ).

Compared with that in ck, GPT activity increased significantly $(P<0.05)$ in the fine roots in all fertilization treatments except in sob and boa. It decreased significantly $(P<0.05)$ in the very fine roots in boa. Reduced application of urea did not significantly influence GPT activity, indicating that $50 \%$ reduction in urea application in the $0-10 \mathrm{~cm}$ layer only influenced the GPT activity in fine roots while $25 \%$ reduction in urea application in the $10-20 \mathrm{~cm}$ layer influenced the GPT activity in both the fine and very fine roots (Fig. 1B).

The GOGAT activity showed a different changing trend from those of the above three enzymes in the biochar application treatments. When $50 \%$ less urea was applied in the 10-20 layer, GOGAT activity in both the very fine and fine roots decreased significantly $(P<0.05$ and 0.01 , respectively) as compared with ck (Fig. 1C). The NR activity increased significantly in sob but decreased in the other treatments as compared with ck and the conventional urea application treatment (Fig. 1D).

Previous studies have shown that AMTs play an important role in $\mathrm{NH}_{4}^{+}$absorption and transportation and directly influence nitrogen metabolism and root development. Significant changes in the transcription level of the AMTs occurred in the sample (Table S1). As shown in Fig. 2, both the $A M T 1 ; 1$ and $A M T 1 ; 3$ gene expression levels were up-regulated or down-regulated in the very fine and fine roots, and their changes became more prominent with larger urea reduction. The expression of AMT1;1 was down-regulated 2.14-fold in soam but up-regulated 3.91-fold in soaf (Table 4). Biochar exhibited a stimulating effect on the express of AMT genes in roots when applied in the $0-10 \mathrm{~cm}$ layer but displayed an inhibiting effect when applied in the $10-20 \mathrm{~cm}$ layer (Fig. 2A). As another group of transcription factors, gdh significantly influenced nitrogen efficiency. The expression of $g d h 2$ in the very fine roots increased by $62 \%$ in soa, decreased significantly in bb, boa, and bob, but did not change much in sb and sob as compared with ck. The expression of gdh in the fine roots decreased significantly in bob but did not change much in the other treatments (Fig. 2B).

\section{Crosstalk between CTK and NR}

The activity of NR is strongly location-dependent and closely related to CTK. It was significantly stimulated in the very fine roots (ranging from 9 to 45 ) but inhibited in the fine roots (ranging from 16 to 27) by CTK (Fig. 3). The results indicate that biochar had enhanced the synergistic effect between CTK and NR. On the one hand, biochar may help to lower the metabolic cost in the fine 


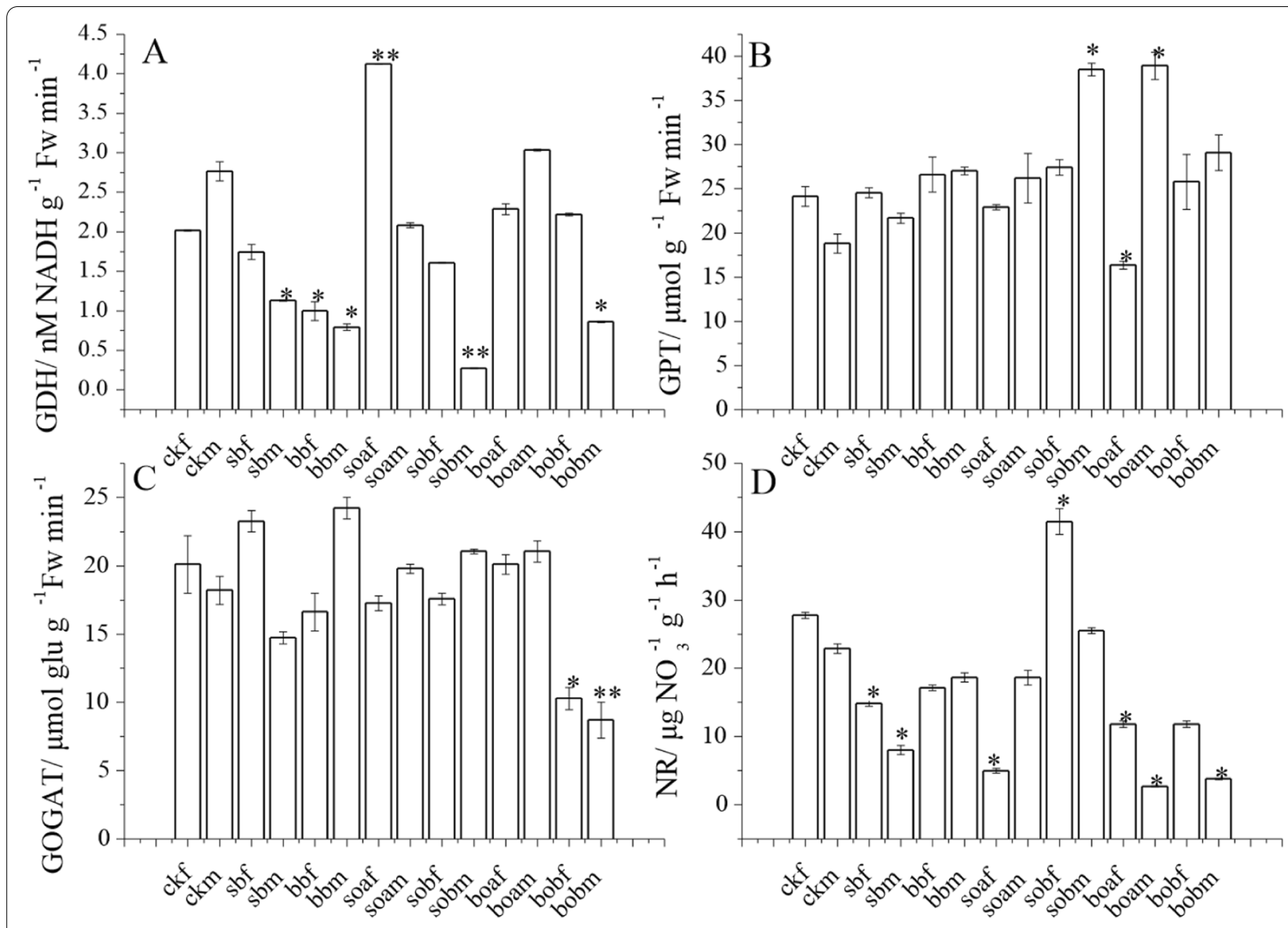

\section{Treatment}

Fig. 1 Activities of the key enzymes involved in nitrogen metabolism in the fine and very fine roots of Gossypium hirsutum in the different treatments. GDH= Glutamic dehydrogenase, GPT = Glutamic-pyruvic transaminase, GOGAT=Glutamic synthase, and NR=Nitrate Reductase. Fine roots are those with diameter between 0.1 and $2 \mathrm{~mm}$, while very fine roots are those with diameter less than $0.1 \mathrm{~mm}$. The treatments include ck (control), sb (conventional $3.76 \mathrm{~g}$ urea $\mathrm{kg}^{-1}$ soil applied in the $0-10 \mathrm{~cm}$ soil layer), bb (conventional $3.76 \mathrm{~g} \mathrm{urea} \mathrm{kg}^{-1}$ soil applied in the 10-20 cm soil layer), soa (urea was reduced by $25 \%$ on the basis of sb plus $37.28 \mathrm{~g}$ biochar $\mathrm{kg}^{-1}$ soil), sob (urea was reduced by $50 \%$ on the basis of sb plus

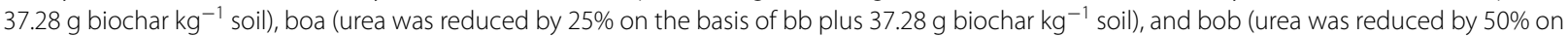
the basis of bb plus $37.28 \mathrm{~g}$ biochar $\mathrm{kg}^{-1}$ soil). The last letters $\mathrm{f}$ and $\mathrm{m}$ of each treatment indicate very fine root and fine root, respectively. Results are presented as mean values for five plants with SE. Asterisk indicates significant difference with a confidence interval at ${ }^{*} P<0.05$ or ${ }^{* *} P<0.01$

roots, and on the other, it may speed up the nitrogen assimilation and turnover in the very fine roots.

\section{The effects of nitrogen reduction combined with biochar application on root traits}

The active absorption area of the very fine roots increased by $9.43 \mathrm{~cm}^{2}$, while that of the fine roots increased by $1.80-9.10 \mathrm{~cm}^{2}$ in soa as compared with the conventional urea application (Fig. 4A). The change in root fresh weight was similar to that of the active absorption area, that is, the fresh weight of the very fine roots decreased markedly while that of the fine roots decreased not much. The fresh weight of the very fine roots in $\mathrm{sb}$ and boa and that of the fine roots in bb decreased significantly $(P<0.05)$ as compared with ck. However, the fresh weight of the fine roots in soa increased significantly $(P<0.01)$ (Fig. 4B). The nitrogen fertilizer agronomic efficiency increased by $1.49 \mathrm{~kg} \mathrm{~kg}^{-1}$ in soa, decreased by $0.91 \mathrm{~kg} \mathrm{~kg}^{-1}$ in boa, and showed an increasing trend in the other treatments (Fig. 4C).

\section{Discussion}

Improvement in the nitrogen use efficiency (NUE) of crops can not only reduce planting costs, but also reduce energy consumption related to chemical fertilizer production, which fundamentally alleviates global climate 


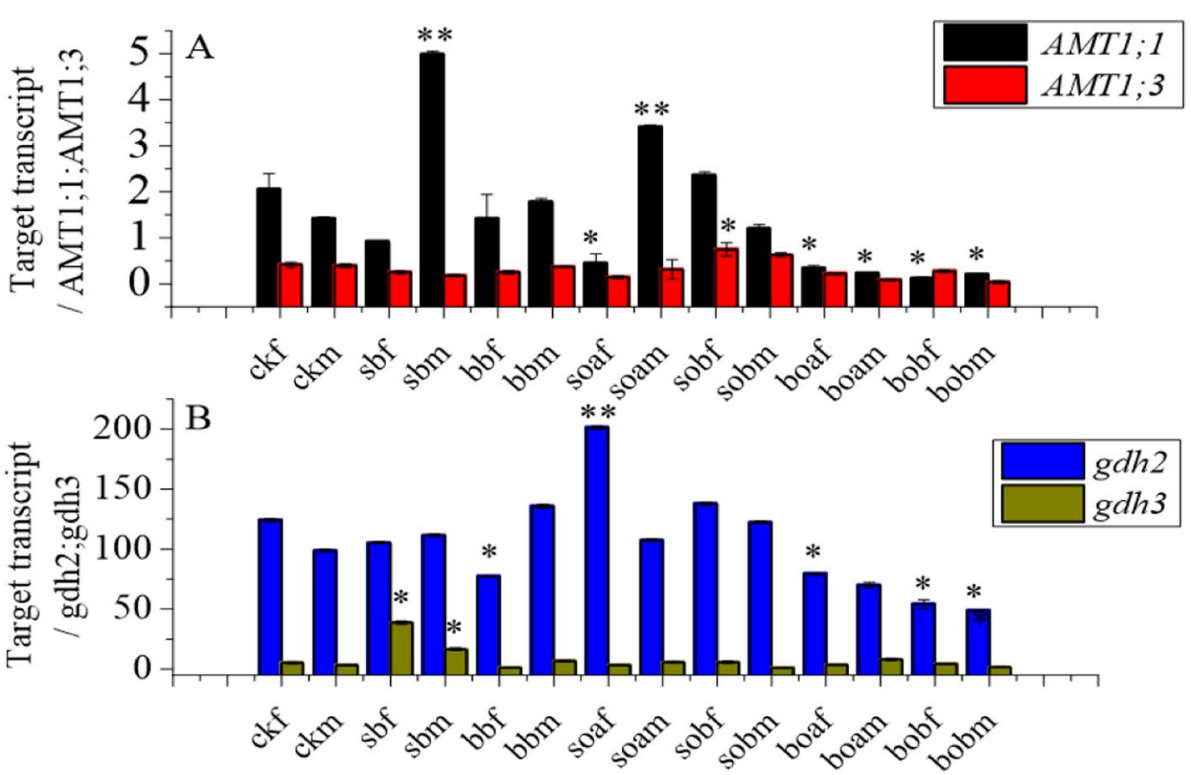

Fig. 2 Expression levels of the AMT1;1, AMT1;3, gdh2, and gdh3 genes in the very fine roots and fine roots of Gossypium hirsutum in the different treatments. Fine roots are those with diameter between 0.1 and $2 \mathrm{~mm}$, while very fine roots are those with diameter less than $0.1 \mathrm{~mm}$. The

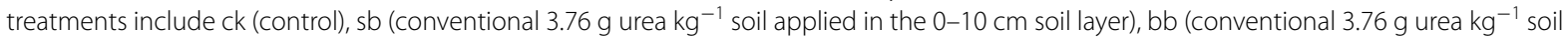
applied in the 10-20 cm soil layer), soa (urea was reduced by $25 \%$ on the basis of sb plus $37.28 \mathrm{~g}$ biochar $\mathrm{kg}^{-1}$ soil), sob (urea was reduced by $50 \%$ on the basis of sb plus $37.28 \mathrm{~g}$ biochar kg ${ }^{-1}$ soil), boa (urea was reduced by $25 \%$ on the basis of bb plus $37.28 \mathrm{~g} \mathrm{biochar} \mathrm{kg}^{-1}$ soil), and bob (urea was reduced by $50 \%$ on the basis of bb plus $37.28 \mathrm{~g}$ biochar $\mathrm{kg}^{-1}$ soil). The last letters $\mathrm{f}$ and $\mathrm{m}$ of each treatment indicate very fine root and fine root, respectively. Results are presented as mean values for five plants with SE. Asterisk indicates significant difference with a confidence interval at ${ }^{*} P<0.05$ or ${ }^{* *} P<0.01$

change [58, 59]. Combined application of biochar and chemical nitrogen fertilizer (e.g., urea) can effectively raise crop yield and NUE by slowing down nitrogen release, regulating microbial diversity, and stimulating nitrification while inhibiting denitrification, as compared with applying chemical fertilizer as the sole nitrogen source [60-62]. There are many studies focused on the increased nitrogen agronomic efficiency resulted from the improved soil nitrogen availability with biochar application, but there are few reports on molecular signals or root phenotypes related to nitrogen availability increase in rhizosphere $[63,64]$. A recent report pointed out that root phenotype and architecture are influenced by soil biophysical and chemical properties such as mineral nitrogen, moisture, and temperature. Therefore, plant roots are of tremendous phenotypic plasticity in their cellular structure, anatomy, cell types, shapes, metabolisms, and biochemical profiles [15], causing big functional differences between root orders. Biochar application may enlarge such differences. For instance, biochar showed stronger effects on the morphological characteristics of roots with $\mathrm{d}<0.5 \mathrm{~mm}$ [29]. Our results show that $25 \%$ urea reduction combined with biochar application led to nitrogen agronomic efficiency increase; in addition, $\mathrm{AOB}$ and mineral nitrogen increased in both the rhizospheres of the very fine and fine roots, with larger increases for the very fine roots. However, some studies found that the diversity of $\mathrm{AOB}$ decreased or did not change with biochar application, which is probably related to the changes in soil $\mathrm{pH}$ and $\mathrm{NH}_{4}{ }^{+}$content [65]. The results suggest from genetic to phenotypic changes.

Extensive studies have shown that exogenous $\mathrm{NH}_{4}{ }^{+}$ triggers multiple specific changes in gene expression, metabolism, hormonal signaling, and root phenotype in rice and Arabidopsis $[66,67]$. Therefore, the fact that improving the affinity of crop roots to $\mathrm{NH}_{4}{ }^{+}$and $\mathrm{NO}_{3}{ }^{-}$ can raise nitrogen utilization efficiency may be closely related to the regulation of the key enzymes involved in nitrogen metabolism [42]. Generally, the activities of $\mathrm{NR}, \mathrm{GDH}$, and GS decrease with the decrease of nitrogen application level. This is because nitrogen levels in the metabolic and non-metabolic pools are decided by the exogenous mineral nitrogen concentration. In contrast, GOGAT is associated with crop nitrogen phenotype, that is, its activity can still be high under low nitrogen levels [5]. For instance, studies show that intraspecific root variation and increase in rhizosphere nitrogen availability improved nitrogen efficiency and promoted crop growth [68]. The activity variation trends of the key enzymes involved in nitrogen 
Table 4 Significantly altered-transcript abundances of gdh and AMT in the very fine $(d<0.1 \mathrm{~mm})$ and fine $(0.1<d<2 \mathrm{~mm})$ roots of Gossypium hirsutum in the different treatments

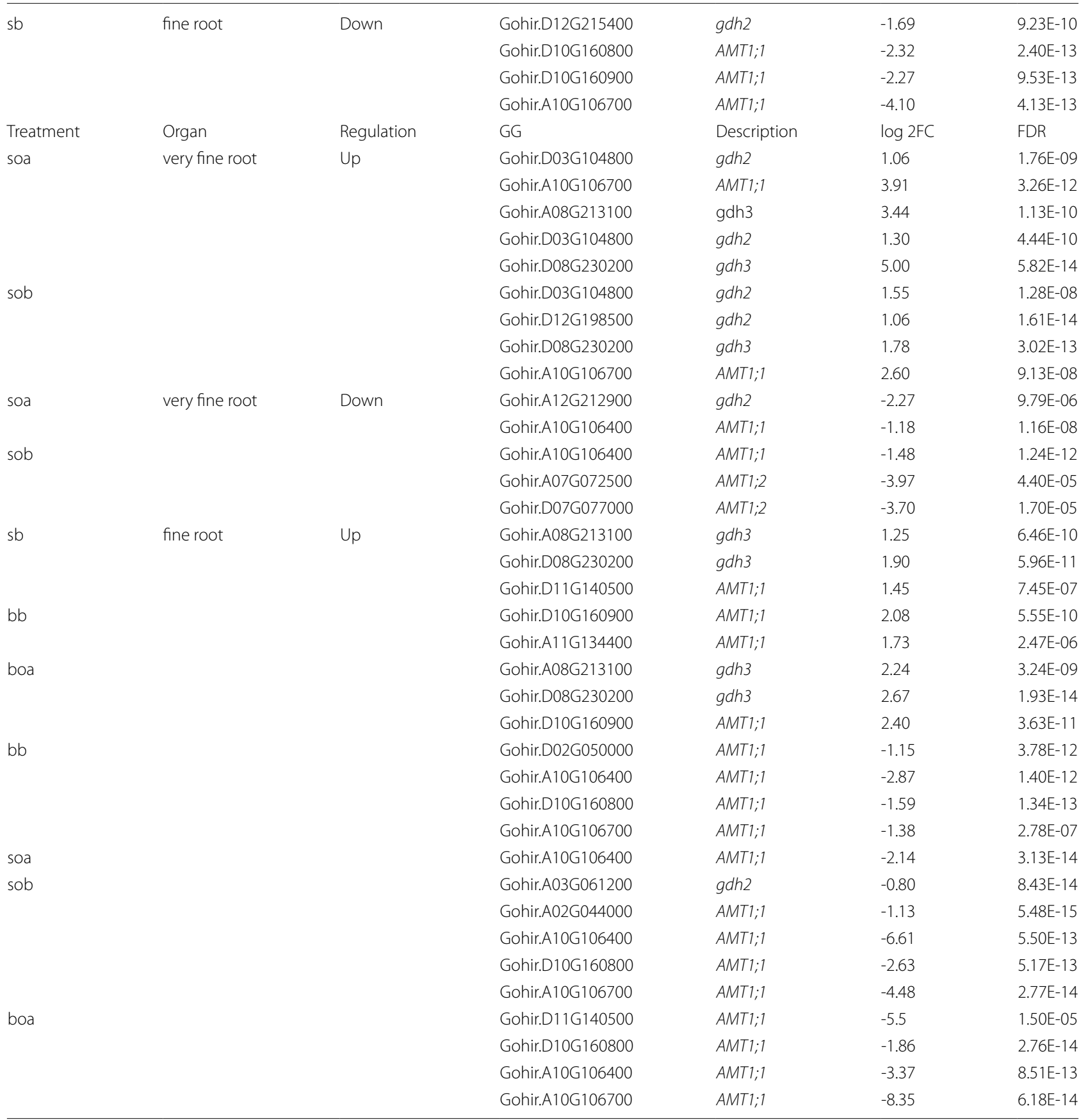

\footnotetext{
Arabidopsis and pium hirsutum genes identification
}

log fold change (log 2FC) between five replicated experiments. Transcripts exhibiting a FDR lower than $0.0001 \%$. $\mathrm{ck}$ (control), sb (conventional $3.76 \mathrm{~g}$ urea $\mathrm{kg}{ }^{-1}$ soil applied in the $0-10 \mathrm{~cm}$ soil layer), bb (conventional nitrogen fertilization in the $10-20 \mathrm{~cm}$ soil layer), soa (urea was reduced by $25 \%$ on the basis of sb plus $37.28 \mathrm{~g}$ biochar $\mathrm{kg}^{-1}$ soil), sob (urea was reduced by $50 \%$ on the basis of sb plus $37.28 \mathrm{~g}$ biochar kg $\mathrm{kg}^{-1}$ soil), boa (urea was reduced by $25 \%$ on the basis of bb plus $37.28 \mathrm{~g}$ biochar $\mathrm{kg}^{-1}$ soil), and bob (urea was reduced by $50 \%$ on the basis of bb plus $37.28 \mathrm{~g}$ biochar kg ${ }^{-1}$ soil). AMT1;1 (Ammonium transporter1;1), AMT1;2 (Ammonium transporter1;2) and gdh2(glutamate dehydrogenase 2 ) 


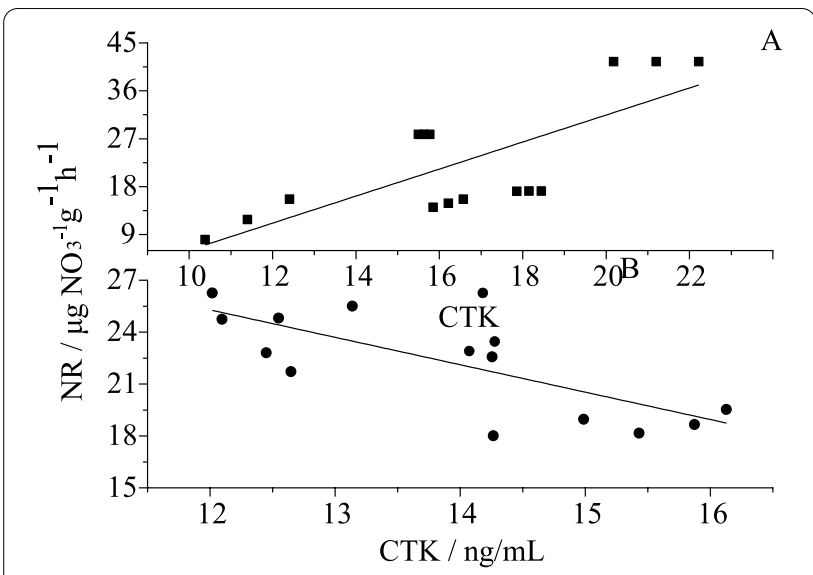

Fig. 3 Relationship between CTK concentration and nitrate reductase activity in the very fine $(\mathbf{A})$ and fine (B) roots of Gossypium hirsutum. Fine roots are those with diameter between 0.1 and $2 \mathrm{~mm}$, while very fine roots are those with diameter less than $0.1 \mathrm{~mm}$. The regression models are $\mathrm{NR}=2.54 \times C \mathrm{CTK}-19.34\left(R^{2}=0.54, P<0.001\right)$ and $\mathrm{NR}=44.29-1.58 \times \mathrm{CTK}\left(R^{2}=0.49, P<0.002\right)$ for the very fine and fine roots, respectively

metabolism observed in this study are in accordance with those reported in the literature. We believe that $A O B$ increase in the rhizosphere of the fine roots is an important cause for the changes in the enzyme activities. Biochar application helps to lower the energy consumption by higher plants in the synthesis of amino acids and nucleic acids, increases $\mathrm{NH}_{4}{ }^{+}$transport into cells by AMT, and is favorable for root phenotype regulation by signaling molecules $[69,70]$.

AMTs in plants are encoded by the AMT1 and AMT2 subfamilies, and AMT1s is associated with efficient $\mathrm{NH}_{4}{ }^{+}$ transport in plants. AMT1;1 in Arabidopsis thaliana is mainly expressed in the roots and leaves, while AMT1;3 is only expressed in the roots; both are sensitive to nitrogen deficiency [71, 72]. When nitrogen is insufficient, $A M T 1 ; 1$ and $A M T 1 ; 3$, would be significantly up-regulated in the root dermis. The up-regulation of $A M T 1 ; 2$, which is associated with carbon and nitrogen metabolism in roots [73], is much more striking. The results of this study showed that $A M T 1 ; 3$ was significantly up-regulated in the very fine roots but obviously down-regulated in the fine roots. This suggests that $A M T 1 ; 3$ in the fine roots was more readily regulated with biochar application. Structural variation in the cortex may be the main factor, and carbon variation in the rhizosphere may contribute to the nitrogen/carbon metabolism in roots to some degree.

Glutamate dehydrogenase $(\mathrm{GDH})$ is a rate-limiting enzyme in ammonium assimilation when plants are under biotic or abiotic stresses. Metabolic processes involving NADH-gdh mainly occur in the roots [74]. In the dark or under stresses, a reversible reaction will occur to provide a carbon framework for the tricarboxylic acid cycle [75], which indicates that GDH is an intermediate of carbon/nitrogen metabolism and is closely related to the environment. In the urea reduction treatments, the
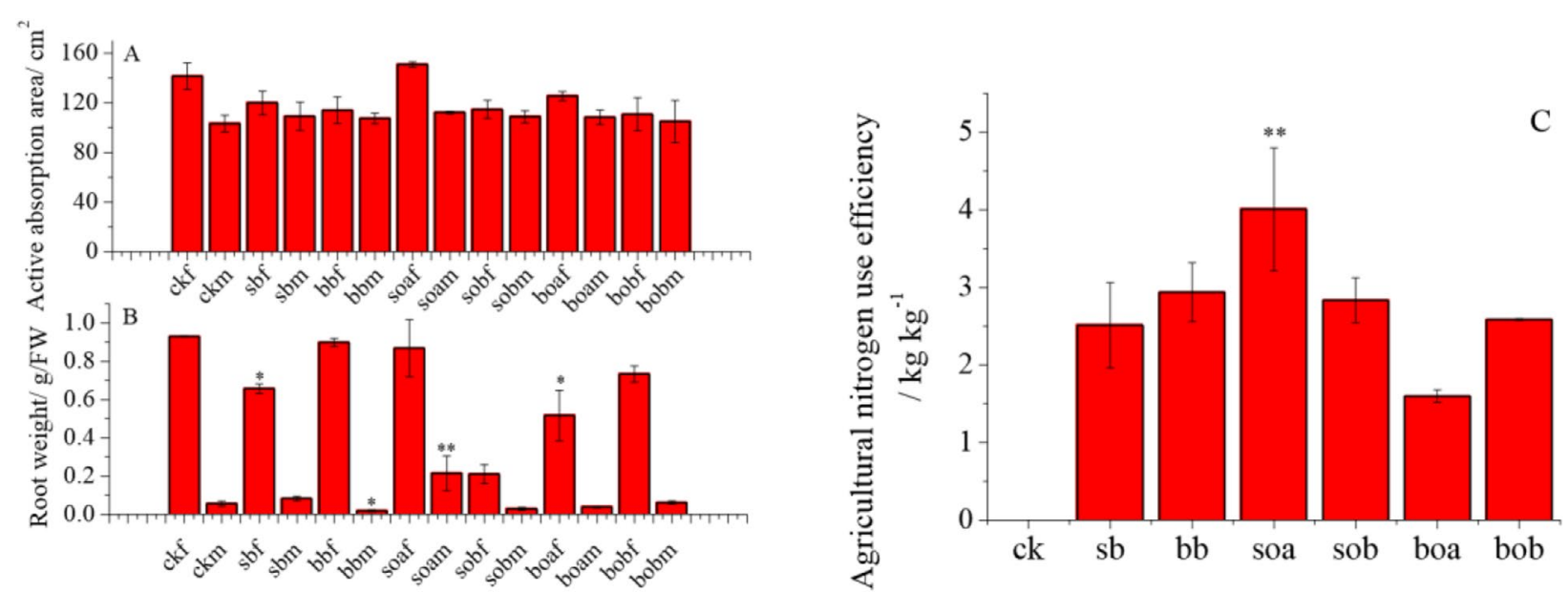

Fig. 4 Active absorption areas and fresh weights of very fine and fine roots and seedling nitrogen agricultural efficiencies of Gossypium hirsutum in the different treatments. Fine roots are those with diameter between 0.1 and $2 \mathrm{~mm}$, while very fine roots are those with diameter less than $0.1 \mathrm{~mm}$.

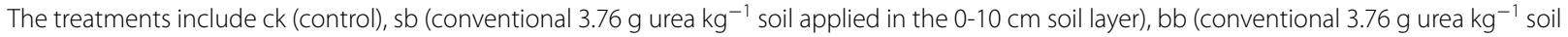
applied in the $10-20 \mathrm{~cm}$ soil layer), soa (urea was reduced by $25 \%$ on the basis of sb plus $37.28 \mathrm{~g}$ biochar $\mathrm{kg}^{-1}$ soil), sob (urea was reduced by $50 \%$

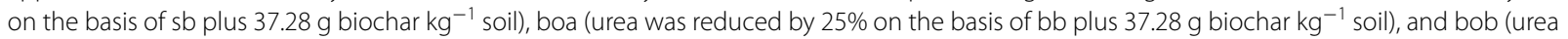
was reduced by $50 \%$ on the basis of bb plus $37.28 \mathrm{~g}$ biochar $\mathrm{kg}^{-1}$ soil). The last letters " $\mathrm{f}$ " and " $\mathrm{m}$ " of each treatment indicate very fine roots and fine roots, respectively. Results are presented as mean values for five plants with SE. Asterisks indicate significant differences with a confidence interval at ${ }^{*} P<0.05$ or ${ }^{* *} P<0.01$ 
GDH activity in the very fine roots increased significantly but that in the fine roots did not change much. The reason may be that the darker and more alkaline $(\mathrm{pH} 9.8)$ environment in these treatments had stimulated GDH protein coding and improved GDH activity [76]. In addition, biochar enhances seedling photosynthesis without inhibiting carbon metabolism [77]. It increases the content of soil organic matter or micro molecule, compensating for the lack of carbon to some degree [78, 79].

Generally, GDH in higher plants has a weak affinity for $\mathrm{NH}_{4}^{+}$, and therefore, $\mathrm{NH}_{4}^{+}$is absorbed mainly by the GS/GOGAT pathway. The results of this study also showed that urea reduction plus biochar application had a strong inhibiting effect on the GOGAT activity in the very fine roots but a mild effect on that in the fine roots. During the process of ammonium assimilation in the induced GS/GOGAT pathway, exogenous ammonium ions may not decrease but even increase (to some extent) because biochar increases the AOB diversity in the fine root rhizosphere, which leads to an increase in $\mathrm{NO}_{3}{ }^{-}$ [80]. The results partly confirm that biochar addition compensated for the reduced urea application to supply plant-needed nitrogen, maintained the stability of amino acids in the nitrogen metabolic pool, and eventually mitigated the effects of reduced urea application to the roots.

NR is another key enzyme in nitrogen metabolism in higher plants. It is strongly influenced by $\mathrm{NO}_{3}{ }^{-}$and light and interacts with hormones [81, 82]. The results showed that NR activity increased by $83 \%$ in sobm, only increased slightly in sobf, and decreased clearly in the other treatments as compared with ck. This suggests that the high concentration of $\mathrm{NO}_{3}{ }^{-}$in the rhizosphere inhibited the growth of the very fine roots while stimulating the development of the fine roots. Consequently, NR activity was changed, which may be related to the fact that biochar can slow down root senescence [83]. The specific environment created by biochar is favorable for the expression of nitrate reductase/nitrite reductase in both the roots and shoots, which can improve plant/crop growth and yield [84]. In addition, a large number of experiments have confirmed that biochar significantly changes the rhizospheric environment [23, 24, 80]. In dark conditions, fine roots produce more CTK and consequently, NR activity increases; biochar application creates a darker environment and promotes nitrogen assimilation (Fig. 3A). Molecular dynamic analysis suggests a possible mechanism underlying the increased NR activity by CTK in the interface of biochar, which is that the small molecules induced by biochar may manage to access the active sites by lowering the energy barrier.

In short, when the urea dose was reduced by $25 \%$ and biochar was applied, $A M T 1 ; 1$ and $g d h 2$ were up-regulated and ammonium assimilation was improved, which was closely related to the crosstalk between AMT and gdh3. Furthermore, the increased NR activity under the stimulation of CTK in the very fine roots also made an important contribution to ammonium assimilation.

\section{Conclusions}

The presented results indicate that the crosstalk between the gdh2 and AMT1;1 signaling pathways influenced the ammonia assimilation of Gossypium hirsutum under the conditions of reduced urea plus biochar application. The nitrogen agronomic efficiency at the seedling stage was $1.51-3.99 \mathrm{~kg} \mathrm{~kg}^{-1}$ higher in the biochar application treatments than in ck. It is speculated that such difference was the direct result of $g d h 2$ upregulation and gdh3 supplementation. Physiologically, the increased GPT and GDH activities were the reason for the higher nitrogen assimilation at the seedling stage under reduced urea plus biochar application conditions. Though high nitrogen assimilation relies heavily on the GDH pathway, it is influenced by the function and development stage of the root system as well.

We further found that CTK can not only activate but also inhibit NR activity under the biochar application condition, which is directly related to the root turnover rate, age, and function. In the biochar application treatments, CTK displayed a stimulating effect on NR activity in the very fine roots but an inhibiting effect in the fine roots. This indicates that the application depth of biochar has a strong effect on root physiology. Overall, the biochar-induced upregulation of $g d h 3$ expression can partially explain the improvement of nitrogen assimilation in the fine roots.

In this study, we demonstrate that the effect of reduced nitrogen usage plus biochar application on nitrogen assimilation efficiency is strongly associated with hormone activation. Knowledge on the differential functions of very fine and fine roots will provide support for effectively improving nitrogen assimilation efficiency. We still need to further explore the interaction between various hormones and nitrogen metabolizing enzymes, that is, to further reveal the mechanism underlying the deep connection between root phenotype and nitrogen metabolism under reduced nitrogen usage plus biochar application. In addition, the influence of biochar on the net nitrogen release rates of different root sequences and its complex relationship with rhizosphere microbial diversity should also be considered as a focus of future research.

\section{Abbreviations}

GDH: Glutamic dehydrogenase; GPT: Glutamic-pyruvic transaminase; GOGAT : Glutamic synthase; NR: Nitrate Reductase; AMTs: Ammonium transporters; AOB: Ammonia oxidizing bacteria; sbf: Very fine root under conventional 
$3.76 \mathrm{~g}$ nitrogen $\mathrm{kg}^{-1}$ soil fertilization in $0 \sim 10 \mathrm{~cm}$ soil layers; sbm: Fine root under conventional $3.76 \mathrm{~g}$ nitrogen $\mathrm{kg}^{-1}$ soil fertilization in $0 \sim 10 \mathrm{~cm}$ soil layers; bbf: Very fine root under conventional nitrogen fertilization in $10 \sim 20 \mathrm{~cm}$ soil layers; bbm: Fine root under conventional nitrogen fertilization in $10 \sim 20 \mathrm{~cm}$ soil layers; soaf: Very fine root under nitrogen was reduced by $25 \%$ on the basis of sb with $37.28 \mathrm{~g}$ biochar $\mathrm{kg}^{-1}$ soil; soam: Fine root under nitrogen was reduced by $25 \%$ on the basis of sb with $37.28 \mathrm{~g}_{\text {biochar } \mathrm{kg}^{-1}}$ soil; sobf: Very fine root under nitrogen was reduced by $50 \%$ on the basis of sb with $37.28 \mathrm{~g}$ biochar $\mathrm{kg}^{-1}$ soil; sobm: Fine root under nitrogen was reduced by $50 \%$ on the basis of sb with $37.28 \mathrm{~g}$ biochar $\mathrm{kg}^{-1}$ soil; boaf: Very fine root under nitrogen was reduced by $25 \%$ on the basis of bb with $37.28 \mathrm{~g}$ biochar $\mathrm{kg}^{-1}$ soil; boam: Fine root under nitrogen was reduced by $25 \%$ on the basis of bb with $37.28 \mathrm{~g}$ biochar $\mathrm{kg}^{-1}$ soil; bobf: Very fine root under nitrogen was reduced by $50 \%$ on the basis of bb with $37.28 \mathrm{~g}$ biochar $\mathrm{kg}^{-1}$ soil; bobm: Fine root under nitrogen was reduced by $50 \%$ on the basis of bb with $37.28 \mathrm{~g}$ biochar $\mathrm{kg}^{-1}$ soil.

\section{Supplementary Information}

The online version contains supplementary material available at https://doi. org/10.1186/s12870-021-03026-1.

Additional file 1: Table S1. Genetic analysis of differences between groups base on DEGseq.

Additional file 2: Figure S1. Heat map showing the expression level of metabolic genes in Gossypium hirsutum. Note: Each column corresponds to a sample, with labels shown below the columns; each row corresponds to a gene, with labels shown on the right of the rows; color denotes standardized gene expression level; the row dendrogram shows hierarchical gene clustering, with closer branches indicating closer gene expression levels; the column dendrogram shows hierarchical sample clustering, with closer branches indicating more similar of the expression patterns of the genes in the samples, that is, more similar the changing trends of the gene expression levels.

\section{Acknowledgements}

We thank Mrs. Yunshu Zhang, Xinjiang Academy of Agricultural Sciences, for providing guidance the determination of soil available nitrogen. We also thank Mrs. Qin Lu, South China Agricultural University, for some experimental ideas.

\section{Authors' contributions}

LF and ZG conceived and designed the experiments. LF, WX, MG and GT performed the experiments and collected the data. LF analyzed the data and wrote the manuscript. ZG, GT and LF interpreted and revised the manuscript. All authors have read and approved this manuscript.

\section{Funding}

The fees for high-throughput sequencing, RT-qPCR, enzyme activity analysis and cytokinin test were supported by the National Natural Science Foundation of China (31660073). The fees for mineral nitrogen and ammonia-oxidizing bacteria were supported by the Deodar in Tianshan Mountains Training Program Foundation for the Talents by Xinjiang Uygur Autonomous Region Science and Technology Department, China (2017XS08), and the publication fees were supported by Key Research and Development Project of Shaanxi Province (2018NY-094)

\section{Availability of data and materials}

The data that support the results are included within the article and its additional files. Other relevant materials are available from the corresponding authors on reasonable request.

\section{Declarations}

Ethics approval and consent to participate Not applicable.

\section{Consent for publication}

Not applicable.

\section{Competing interests}

The authors declare that they have no competing interests.

\section{Author details}

${ }^{1}$ College of Natural Resources and Environment, Northwest Key Laboratory of Plant Nutrition and Agro-Environment, Ministry of Agriculture, Northwest A \& F University, Yangling 712100, China. ${ }^{2}$ Xinjiang Academy of Agricultural Sciences Institute of Soil Fertilizer and Water Conservation, Urumqi 830092 , China. ${ }^{3}$ Xinxiang Academy of Agricultural Sciences Institute of Microbial Application, Urumqi 830091, China.

Received: 17 June 2020 Accepted: 10 May 2021

Published online: 11 June 2021

\section{References}

1. Jandl G, Eckhardt KU, Bargmann I, Kucke M, Greef JM, Knicker H, Leinweber P. Hydrothermal carbonization of biomass residues: mass spectrometric characterization for ecological effects in the soil-plant system. J Environ Qual. 2013:42(1):199-207.

2. Ahmed MJ, Okoye PU, Hummadi EH, Hameed BH. High-performance porous biochar from the pyrolysis of natural and renewable seaweed (Gelidiella acerosa) and its application for the adsorption of methylene blue. Biores Technol. 2019;278:159-64.

3. Weihrich S, Xing XJ. Screening of synergetic catalytic effects of salts dominant in sewage sludge on corn stalk derived hydro and biochar. Bioenerg Res. 2020;(Part 1):1-13.

4. Sekaran U, Sandhu SS, Qiu YY, Kurnar S, Hernandez JLG. Biochar and manure addition influenced soil microbial community structure and enzymatic activities at eroded and depositional landscape positions. Land Degrad Dev. 2020;31(7):894-908.

5. Abbasifar A, ValizadehKaji B, Iravani MA. Effect of green synthesized molybdenum nanoparticles on nitrate accumulation and nitrate reductase activity in spinach. J Plant Nutr. 2020;43(1):13-27.

6. Liang J, Tang S, Gong J, Zeng G, Tang W, Song B, Zhang P, Yang Z, Luo Y. Responses of enzymatic activity and microbial communities to biochar/ compost amendment in sulfamethoxazole polluted wetland soil. J Hazard Mater. 2020;385:121533.

7. Mehdizadeh L, Moghaddam M, Lakzian A. Amelioration of soil properties, growth and leaf mineral elements of summer savory under salt stress and biochar application in alkaline soil. Sci Hortic-Amsterdam. 2020:267:109319.

8. Chrysargyris A, Prasad M, Kavanagh A, Tzortzakis N. Biochar type, ratio, and nutrient levels in growing media affects seedling production and plant performance. Agronomy-Basel. 2020;10(9):1421.

9. Dong D, Wang C, Van Zwieten L, Wang H, Jiang P, Zhou M, Wu W. An effective biochar-based slow-release fertilizer for reducing nitrogen loss in paddy fields. J Soil Sediment. 2020;20(8):3027-40.

10. Haider G, Joseph S, Steffens D, Muller C, Taherymoosavi S, Mitchell D, Kammann Cl. Mineral nitrogen captured in field-aged biochar is plantavailable. Sci Rep-Uk. 2020;10(1):1.

11. Asadyar $L, X u C Y$, Wallace HM, Xu Z, Reverchon F, Bai SH. Soil-plant nitrogen isotope composition and nitrogen cycling after biochar applications. Environ Sci Pollut Res Int. 2020;28:6684-90.

12. Fouladidorhani M, Shayannejad M, Shariatmadari H, Mosaddeghi MR, Arthur E. Biochar, manure, and super absorbent increased wheat yields and salt redistribution in a saline-sodic soil. Agronomy J. 2020;112:5193.

13. Li SL, Wang S, Fan MC, Wu Y, Shangguan ZP. Interactions between biochar and nitrogen impact soil carbon mineralization and the microbial community. Soil Till Res. 2020;196:104437.

14. Wu X, Sun Y, Deng L, Meng Q, Jiang X, Bello A, Sheng S, Han Y, Zhu H, Xu $X$. Insight to key diazotrophic community during composting of dairy manure with biochar and its role in nitrogen transformation. Waste Manag. 2020;105:190-7. 
15. Saleem M, Law AD, Sahib MR, Pervaiz ZH, Zhang QM. Impact of root system architecture on rhizosphere and root microbiome. Rhizosphere. 2018;6:47-51.

16. Luo Y, Dungait JAJ, Zhao XR, Brookes PC, Durenkamp M, Li GT, Lin QM. Pyrolysis temperature during biochar production alters its subsequent utilization by microorganisms in an acid arable soil. Land Degrad Dev. 2018;29(7):2183-8.

17. Xu YF, Liu GL, Hua YM, Wan XQ, Hu JL, Zhu DW, Zhao JW. The diversity of comammox bacteria and the effect of sewage discharge on their abundance in eutrophic lake sediments. J Soils Sediments. 2020;20(5):2495-503.

18. Farhangi-Abriz S, Torabian S. Biochar increased plant growth-promoting hormones and helped to alleviates salt stress in common bean seedlings. J Plant Growth Regul. 2018;37(2):591-601.

19. Yang E, Meng J, Hu H, Cheng D, Zhu C, Chen W. Effects of organic molecules from biochar-extracted liquor on the growth of rice seedlings. Ecotoxicol Environ Saf. 2019;170:338-45.

20. Zaitun Z, Yusnizar Y, Yunilasari M, Persada A. Effects of biochar residue and cow manure residue on entisol chemical properties, growth, and production of peanut (Arachis hypogaea L.) in second planting season. IOP Conf Earth Environ Sci. 2020;583(1):012011-7.

21. Rafique M, Ortas I, Rizwan M, Chaudhary HJ, Gurmani AR, Hussain Munis MF. Residual effects of biochar and phosphorus on growth and nutrient accumulation by maize (Zea mays L.) amended with microbes in texturally different soils. Chemosphere. 2020;238:124710.

22. Di Lonardo S, Vaccari FP, Baronti S, Capuana M, Bacci L, Sabatini F, Lambardi M, Miglietta F. Biochar successfully replaces activated charcoal for in vitro culture of two white poplar clones reducing ethylene concentration. Plant Growth Regul. 2013;69(1):43-50.

23. Olmo M, Lozano AM, Barron V, Villar R. Spatial heterogeneity of soil biochar content affects soil quality and wheat growth and yield. Sci Total Environ. 2016;562:690-700.

24. Romdhane L, Awad YM, Radhouane L, Dal C, CortivoBarion G, Panozzo A, Vamerali T. Wood biochar produces different rates of root growth and transpiration in two maize hybrids (Zea mays L.) under drought stress. Arch Agron Soil Sci. 2019;65(6):846-66.

25. Sun CX, Hao L, Wang D, Li C, Zhang C, Chen X, Fu J, Zhang YL. Nitrogen utilisation and metabolism in maize (Zea mays L.) plants under different rates of biochar addition and nitrogen input conditions. Plant Biol (Stuttg). 2019;21(5):882-90

26. Danish S, Zafar-UI-Hye M. Co-application of ACC-deaminase producing PGPR and timber-waste biochar improves pigments formation, growth and yield of wheat under drought stress. Sci Rep. 2019;9(1):5999.

27. Jaiswal AK, Alkan N, Elad Y, Sela N, Philosoph AM, Graber ER, Frenkel O. Molecular insights into biochar-mediated plant growth promotion and systemic resistance in tomato against Fusarium crown and root rot disease. Sci Rep-Uk. 2020;10(1):13934.

28. Yang DQ, Liu F, Bai Y, Zeng J, Hao HN, Yue X, Hu CX, Long SR, Liu RD, Wang $Z Q$, et al. Functional characterization of a glutathione S-transferase in Trichinella spiralis invasion, development and reproduction. Vet Parasitol. 2020:109128.

29. Zhu Q, Kong LJ, Xie FT, Zhang HJ, Wang HY, Ao X. Effects of biochar on seedling root growth of soybeans. Chilean J Agric Res. 2018;78(4):549-58.

30. Farhangi-Abriz S, Torabian S. Antioxidant enzyme and osmotic adjustment changes in bean seedlings as affected by biochar under salt stress. Ecotoxicol Environ Saf. 2017:137:64-70.

31. Zhang Z, Dong X, Wang S, Pu X. Benefits of organic manure combined with biochar amendments to cotton root growth and yield under continuous cropping systems in Xinjiang, China. Sci Rep. 2020;10(1):4718.

32. Hashem A, Kumar A, Al-Dbass AM, Alqarawi AA, Al-Arjani AF, Singh G, Farooq M, Abd Allah EF. Arbuscular mycorrhizal fungi and biochar improves drought tolerance in chickpea. Saudi J Biol Sci. 2019;26(3):614-24.

33. Bian R, Joseph S, Shi W, Li L, Taherymoosavi S, Pan G. Biochar DOM for plant promotion but not residual biochar for metal immobilization depended on pyrolysis temperature. Sci Total Environ. 2019:662:571-80

34. Harel YM, Mehari ZH, Rav-David D, Elad Y. Systemic resistance to gray mold induced in tomato by benzothiadiazole and Trichoderma harzianum T39. Phytopathology. 2014;104(2):150-7.
35. Du YD, Zhang XQ, Shu L, Feng Y, Lv C, Liu HQ, Xu F, Wang Q, Zhao CC, Kong Q. Safety evaluation and ibuprofen removal via an Alternanthera philoxeroides-based biochar. Environ Sci Pollut Res Int. 2020;25(11):11356.

36. Waqas M, Shahzad R, Hamayun M, Asaf S, Khan AL, Kang SM, Yun S, Kim KM, Lee IJ. Biochar amendment changes jasmonic acid levels in two rice varieties and alters their resistance to herbivory. PLoS One. 2018;13(1):e0191296.

37. French $E$, lyer-Pascuzzi AS. A role for the gibberellin pathway in biocharmediated growth promotion. Sci Rep. 2018;8(1):5389.

38. Racioppi M, Tartaglia M, De la Rosa JM, Marra M, Lopez-Capel E, Rocco M. Response of ancient and modern wheat Varieties to biochar application: effect on hormone and gene expression involved in germination and growth. Agronomy. 2020;10(1):5.

39. Hale L, Luth M, Crowley D. Biochar characteristics relate to its utility as an alternative soil inoculum carrier to peat and vermiculite. Soil Biol Biochem. 2015;81:228-35.

40. Huang WK, Ji HL, Gheysen G, Debode J, Kyndt T. Biochar-amended potting medium reduces the susceptibility of rice to root-knot nematode infections. BMC Plant Biol. 2015;15:267.

41. Tsago Y, Chen ZY, Cao H, Sunusi M, Khan AU, Shi CH, Jin XL. Rice gene, OsCKX2-2, regulates inflorescence and grain size by increasing endogenous cytokinin content. Plant Growth Regul. 2020;92(2):283-94.

42. Kumar V, Kim SH, Priatama RA, Jeong JH, Adnan MR, Saputra BA, Kim CM, Je BI, Park SJ, Jung KH, et al. NH4+ suppresses NO3--dependent lateral root growth and alters gene expression and gravity response in OSAMT1 RNAi mutants of rice (Oryza sativa). J Plant Biol. 2020;63(5):391-407.

43. Jenkins JR, Viger M, Arnold EC, Harris ZM, Ventura M, Miglietta F, Girardin C, Edwards RJ, Rumpel C, Fornasier F, et al. Biochar alters the soil microbiome and soil function: results of next-generation amplicon sequencing across Europe. Glob Change Biol Bioenergy. 2017;9(3):591-612.

44. Ren TT, Yu XY, Liao JH, Du YN, Zhu YJ, Jin L, Wang BT, Xu HM, Xiao WY, Chen $\mathrm{HYH}$, et al. Application of biogas slurry rather than biochar increases soil microbial functional gene signal intensity and diversity in a poplar plantation. Soil Biol Biochem. 2020;146:107825.

45. Pervaiz ZH, Contreras J, Hupp BM, Lindenberger JH, Chen D, Zhang Q, Wang C, Twigg P, Saleem M. Root microbiome changes with root branching order and root chemistry in peach rhizosphere soil. Rhizosphere. 2020;16:100249.

46. Deja-Muylle A, Parizot B, Motte H, Beeckman T. Exploiting natural variation in root system architecture via genome-wide association studies. J Exp Bot. 2020;71(8):2379-89.

47. Cervilla LM, Blasco B, Rios JJ, Rosales MA, Rubio-Wilhelmi MM, SanchezRodriguez E, Romero L, Ruiz JM. Response of nitrogen metabolism to boron toxicity in tomato plants. Plant Biol. 2009;11(5):671-7.

48. Kasim W, Dewedar S. Amino acids and soluble protein profile of radish seedlings under salt stress as affected by GA3priming. Indian J Plant Physiol. 2006;11:75-82.

49. Yang J, Peng S, Visperas RM, Sanico AL, Zhu Q, Gu S. Grain filling pattern and cytokinin content in the grains and roots of rice plants. Plant Growth Regul. 2000;30(3):261-70.

50. Kim D, Landmead B, Salzberg SL. HISAT: a fast spliced aligner with low memory requirements. Nat Methods. 2015;12(4):357-U121.

51. Pertea M, Pertea GM, Antonescu CM, Chang TC, Mendell JT, Salzberg SL. StringTie enables improved reconstruction of a transcriptome from RNAseq reads. Nat Biotechnol. 2015;33(3):290.

52. Li B, Dewey C. RSEM: accurate transcript quantification from RNASeq data with or without a reference genome. BMC Bioinformatics. 2011;12:323.

53. Robinson MD, McCarthy DJ, Smyth GK. edgeR: a Bioconductor package for differential expression analysis of digital gene expression data. Bioinformatics. 2010;26(1):139-40.

54. Scavo A, Restuccia A, Lombardo S, Fontanazza S, Abbate C, Pandino G, Anastasi U, Onofri A, Mauromicale G. Improving soil health, weed management and nitrogen dynamics by Trifolium subterraneum cover cropping. Agron Sustain Dev. 2020;40(3):18.

55. Osburn ED, Barrett JE. Abundance and functional importance of complete ammonia-oxidizing bacteria (comammox) versus canonical nitrifiers in temperate forest soils. Soil Biol Biochem. 2020;145:107801.

56. Sarasin A, Kauffmann A. Overexpression of DNA repair genes is associated with metastasis: a new hypothesis. Mutat Res-Rev Mutat. 2008:659(1-2):49-55. 
57. Hong FX, Breitling R, McEntee CW, Wittner BS, Nemhauser JL, Chory J. RankProd: a bioconductor package for detecting differentially expressed genes in meta-analysis. Bioinformatics. 2006;22(22):2825-7.

58. Al Tawaha AR, Singh S, Singh V, Kafeel U, Irfan M, Kumari A, Imran, Amanullah DR, Al Tawaha AR, Qaisi A, et al. Improving water use efficiency and nitrogen use efficiency in rice through breeding and genomics approaches. 2020. p. 307-37.

59. Yoon D-K, Ishiyama K, Suganami M, Tazoe Y, Watanabe M, Imaruoka S, Ogura M, Ishida H, Suzuki Y, Obara M, et al. Transgenic rice overproducing Rubisco exhibits increased yields with improved nitrogen-use efficiency in an experimental paddy field. Nature Food. 2020;1(2):134-9.

60. Verma B, Reddy MS. Biochar augmentation improves ectomycorrhizal colonisation, plant growth and soil fertility. Soil Res. 2020;58(7):673-82.

61. Liao J, Liu X, Hu A, Song H, Chen X, Zhang Z. Effects of biochar-based controlled release nitrogen fertilizer on nitrogen-use efficiency of oilseed rape (Brassica napus L.). Sci Rep-Uk. 2020;10:1.

62. Yu P, Li Q, Huang L, Qin K, Niu G. gu M: the effects of mixed hardwood biochar, mycorrhizae, and fertigation on container tomato and pepper plant growth. Sustainability-Basel. 2020;12:7072.

63. Cui E-P, Gao F, Liu Y, Fan X-Y, Li Z-Y, Du Z-J, Hu C, Neal AL. Amendment soil with biochar to control antibiotic resistance genes under unconventional water resources irrigation: Proceed with caution. Environ Pollut. 2018;240:475-84

64. Ma GX, Mao HP, Bu Q, Han LH, Shabbir A, Gao F. Effect of compound biochar substrate on the root growth of cucumber plug seedlings. Agronomy-Basel. 2020;10(8):1080.

65. Shi YL, Liu XR, Zhang QW, Gao PL, Ren JQ. Biochar and organic fertilizer changed the ammonia-oxidizing bacteria and archaea community structure of saline-alkali soil in the North China Plain. J Soil Sediment. 2020;20(1):12-23.

66. Kittipornkul P, Treesubsuntorn C, Thiravetyan P. Effect of exogenous catechin and salicylic acid on rice productivity under ozone stress: the role of chlorophyll contents, lipid peroxidation, and antioxidant enzymes. Environ Sci Pollut Res. 2020;27(20):25774-84.

67. Kim H, Zhou J, Kumar D, Jang G, Ryu KH, Sebastian J, Miyashima S, Helariutta Y, Lee J-Y. SHORTROOT-mediated intercellular signals coordinate phloem development in arabidopsis roots. Plant Cell. 2020;32(5):1519-35.

68. Billah MM, Ahmad W, Ali M. Biochar particle size and Rhizobia strains effect on the uptake and efficiency of nitrogen in lentils. J Plant Nutr. 2019;42(15):1709-25

69. Ganz P, ljato T, Porras-Murillo R, Stuhrwohldt N, Ludewig U, Neuhauser B. A twin histidine motif is the core structure for high-affinity substrate selection in plant ammonium transporters. J Biol Chem. 2020;295(10):3362-70

70. Xiao R, Zhang H, Tu ZN, Li RH, Li SL, Xu ZY, Zhang ZQ. Enhanced removal of phosphate and ammonium by MgO-biochar composites with $\mathrm{NH} 3$ center dot $\mathrm{H} 2 \mathrm{O}$ hydrolysis pretreatment. Environ Sci Pollut Res. 2020;27(7):7493-503.

71. Davidson H, Shrestha R, Cornulier T, Douglas A, Travis T, Johnson D, Price $\mathrm{AH}$. Spatial effects and GWA mapping of root colonization assessed in the interaction between the rice diversity panel 1 and an arbuscular mycorrhizal fungus. Front Plant Sci. 2019;10:633.
72. Hao DL, Zhou JY, Yang SY, Qi W, Yang KJ, Su YH. Function and regulation of ammonium transporters in plants. Int J Mol Sci. 2020;21(10):3557.

73. Zhao Y, Liu Z, Duan F, An X, Liu X, Hao D, Gu R, Wang Z, Chen F, Yuan L. Overexpression of the maize ZmAMT1;1a gene enhances root ammonium uptake efficiency under low ammonium nutrition. Plant Biotechnol Rep. 2018;12(1):47-56.

74. lqual A, Dong Q, Wang Z, Wang XR, Gui HP, Zhang HH, Pang NC, Zhang $X L$, Song MZ. Growth and nitrogen metabolism are associated with nitrogen-use efficiency in cotton genotypes. Plant Physiol Bioch. 2020;149:61-74.

75. Kishorekumar R, Bulle M, Wany A, Gupta KJ. An Overview of important enzymes involved in nitrogen assimilation of plants. Methods Mol Biol. 2020;2057:1-13.

76. Marchi L, Degola F, Baruffini E, Restivo FM. How to easily detect plant $\mathrm{NADH}$-glutamate dehydrogenase $(\mathrm{GDH})$ activity? A simple and reliable in planta procedure suitable for tissues, extracts and heterologous microbial systems. Plant Sci. 2020;304:110714.

77. Abideen Zainul, Koyro Hans-Werner, Huchzermeyer Bernhard, Gul Bilquees, Khan Ajmal M. Impact of a biochar or a biochar-compost mixture on water relation, nutrient uptake and photosynthesis of Phragmites karka. Pedosphere. 2020;30(04):38-49.

78. Eizenberg H, Plakhine D, Ziadne H, Tsechansky L, Graber ER. Nonchemical control of root parasitic weeds with biochar. Front Plant Sci. 2017:8:939.

79. Ramadan MM, Asran A, Abd-Elsalam KA. 16 - Micro/nano biochar for sustainable plant health: present status and future prospects. In: Carbon Nanomaterials for Agri-Food and Environmental Applications. Edited by Abd-Elsalam KA. Elsevier. 2020. p. 323-57.

80. Lu SM, Liu XG, Liu C, Cheng GF, Shen HY. Influence of photoinhibition on nitrification by ammonia-oxidizing microorganisms in aquatic ecosystems. Rev Environ Sci Bio. 2020;19(3):531-42.

81. Creighton MT, Sanmartin M, Kataya ARA, Averkina IO, Heidari B, Nemie-Feyissa D, Sanchez-Serrano JJ, Lillo C. Light regulation of nitrate reductase by catalytic subunits of protein phosphatase $2 \mathrm{~A}$. Planta. 2017;246(4):701-10

82. Kataria S, Jain M, Tripathi DK, Singh VP. Involvement of nitrate reductasedependent nitric oxide production in magnetopriming-induced salt tolerance in soybean. Physiol Plant. 2020;168(2):422-36.

83. Blaser SRGA, Koebernick N, Spott O, Thiel E, Vetterlein D. Dynamics of localised nitrogen supply and relevance for root growth of Vicia faba ('Fuego') and Hordeum vulgare ('Marthe') in soil. Sci Rep-Uk. 2020;10(1):1.

84. Moradi R, Pourghasemian N, Naghizadeh M. Effect of beeswax waste biochar on growth, physiology and cadmium uptake in saffron. J Clean Prod. 2019;229:1251-61.

\section{Publisher's Note}

Springer Nature remains neutral with regard to jurisdictional claims in published maps and institutional affiliations.

Ready to submit your research? Choose BMC and benefit from:

- fast, convenient online submission

- thorough peer review by experienced researchers in your field

- rapid publication on acceptance

- support for research data, including large and complex data types

- gold Open Access which fosters wider collaboration and increased citations

- maximum visibility for your research: over $100 \mathrm{M}$ website views per year

At BMC, research is always in progress.

Learn more biomedcentral.com/submissions 